\title{
ULNAR NERVE INJURY ASSOCIATED WITH ANAESTHESIA
}

\author{
M.G.P. CAMERoN ${ }^{1}$ and O.J. Stewart ${ }^{2}$
}

\section{INTRODUCTION}

REPORTS of peripheral nerve pathology associated with anaesthesia have appeared in the medical literature during the past 80 years. Budinger ${ }^{1}$ was the first to recognize that the majority of these post-operative neuropathies were due to malpositioning on the operating table. Garriques ${ }^{2}$ reviewed the literature and reported five cases. He emphasized the importance of proper positioning of the patient during anaesthesia because of the effects of pressure and stretching on the nerves. Publications which stress the importance of proper positioning of unconscious patients have continued to appear (Wood, ${ }^{3}$ Clausen, ${ }^{4}$ Slocum, O'Neal and Allen, ${ }^{5}$ Nicholson and Eversole, ${ }^{6}$ Lincoln and Sawyer ${ }^{7}$ ). Britt and Gordon ${ }^{8}$ expressed the view that nerve injuries associated with anaesthesia are preventable. They pointed out that the patient is unable to complain of postural insults when his perceptual powers are no longer intact and is more susceptible to the effects of unphysiological positions when the muscle tonus is reduced. Jones ${ }^{9}$ stated that more attention should be paid to the coincidence in these patients of medical diseases which have wellestablished neurological elements in their clinico-pathological manifestations. Wylie and Churchill-Davidson ${ }^{10}$ believe that in the assessment of any post-operative nerve palsy, a knowledge of the pre-operative neurological condition is of considerable importance. They state that not only is a diseased nerve more susceptible to trauma but the debilitating effects of having surgery and anaesthesia, even without having any localized factor in the nerve itself, may accentuate pre-existing neurological disease.

The frequency of lesions in the ulnar nerve which are associated with anaesthesia is difficult to determine. Wood ${ }^{3}$ reported that nerve injuries to the unconscious patient are not frequent, but are extremely disconcerting and that probably the nerve most commonly injured is the ulnar nerve. Woltman ${ }^{11}$ reported the causes of paralysis of the ulnar nerve in 300 cases. Operating-room trauma was given as the cause in 11 per cent. Payan ${ }^{12}$ studied lesions of 50 ulnar nerves and gave the aetiology in eight ( 16 per cent) as compression during general anaesthesia. He reported that lesions in the post-operative group were far more severe than those in the patients in which bed rest seemed to be responsible.

The first case of a lesion in an ulnar nerve following an anaesthetic was reported by De Leon. ${ }^{13}$ Reports of 52 other cases were found in the literature (Table I).

From the Department of Physical Medicine and Rehabilitation, University of Western Ontario, Victoria, University and Westminster Hospitals, London, Ontario.

1 Professor and Head, Department of Physical Medicine and Rehabilitation, University of Western Ontario, formerly Chief of Service, Department of Physical Medicine and Rehabilitation, Victoria Hospital.

2 Associate Professor, Department of Physical Medicine and Rehabilitation, Director of Electrodiagnostic Laboratories, University and Westminster Hospitals. 
TABLE I

CAses Reported in Literature

\begin{tabular}{|c|c|c|}
\hline Author & Year & $\begin{array}{l}\text { Number } \\
\text { of cases }\end{array}$ \\
\hline De Léon ${ }^{13}$ & 1901 & 1 \\
\hline Gurdjian, E.S. ${ }^{14}$ & 1931 & 1 \\
\hline Dhunér, K.G. ${ }^{15}$ & 1950 & 8 \\
\hline Childress, H.M. ${ }^{16}$ & 1956 & 4 \\
\hline Mumenthaler, M. ${ }^{17}$ & 1961 & 12 \\
\hline Estridge, M.N. \& Smith, R.A. ${ }^{18}$ & 1962 & 2 \\
\hline Copp, E.P.19 & 1965 & 3 \\
\hline Jones, H.D. ${ }^{9}$ & 1967 & 1 \\
\hline Payan, J.12 & 1969 & 8 \\
\hline Engkvist, $0 .{ }^{20}$ & 1972 & 12 \\
\hline
\end{tabular}

This report is submitted to draw attention to the fact that in spite of the advances in anaesthesia, surgery and care of the unconscious patient, compression injuries to the ulnar nerve continue to occur in such patients. Our interest in the lesions was initiated by 35 cases referred to the electro-diagnostic laboratories of the Departments of Physical Medicine and Rehabilitation, Victoria Hospital, Westminister Hospital and University Hospital, London, Ontario, during a period from 1965 to 1974.

\section{METHOD}

A review was made of the records of the electrodiagnostic laboratories of 159 patients (114 males and 45 females) who were referred with clinical evidence of pathology in one or both ulnar nerves. The aetiological factors were recorded (Table II). The 35 cases (lines 1 and 2, Table II) who were referred with a history of developing symptoms after an anaesthetic form the basis of this report. Cases where the nerve roots, brachial plexus or ulnar nerve might have been damaged by surgical procedures or pre-operative trauma were not included. In the post-anaesthetic cases, the clinical and the laboratory records were reviewed. Where possible, additional reports were obtained from referring physicians regarding follow-up

TABLE 11

Aetiological factors in Ulnar Nerve Pathology (159 Cases)

\begin{tabular}{llrr}
\hline \multicolumn{1}{c}{ Cause } & & No. & $\%$ \\
\hline Compression & General Anaesthesia & 34 & 21.4 \\
& Local Anaesthesia & 1 & 0.6 \\
& Drug overdose & 1 & 0.6 \\
& Bed rest & 5 & 3.2 \\
Accidents & Motor Vehicle & 21 & 13.2 \\
& Industrial & 11 & 6.9 \\
Local & Others & 14 & 8.8 \\
abnormalities & Over 6 months & 7 & 4.4 \\
Unknown & Recent & 9 & 5.7 \\
& & 56 & 35.2 \\
\hline
\end{tabular}


examinations and from patients regarding symptoms and degree of disability. In 15 of the cases, the final report which was available was the one recorded at the time of the electrodiagnostic examination.

The following information was recorded:

\section{Clinical Records}

1. Age

2. Sex

3. Surgical procedure

4. Type of anaesthetic

5. Use of muscle relaxants

6. Duration of anaesthetic

7. Interval between anaesthetic and onset of symptoms

8. Type of symptoms

9. Side of lesion

10. Interval between symptoms and referral for electrodiagnosis

11. Specialty of referring physicians

12. Predisposing causes

13. Duration and progression of symptoms

14. Surgery for transposition of nerve
Laboratory Records

1. Nerve Conduction Studies (motor and sensory)

(a) Distal latency

(b) Velocity in forearm segment

(c) Velocity in segment crossing the elbow

(d) Difference (in percent) between the two velocities

(e) Appearance of evoked potentials

2. Electromyography

(a) Evidence of denervation in:

1. Abductor digiti quinti

2. First dorsal interosseous

3. Flexor carpi ulnaris

Unfortunately, complete clinical records were not available in all of the cases where the operation was not done in a local hospital. Because the referrals to the electrodiagnostic laboratory were made over a period of eight years, the scheme of investigation and the models of the electromyograph and stimulator varied. However, all studies were designed to detect evidence of changes in nerve conduction velocity and of denervation in muscles supplied by the ulnar nerve. Prior to 1969 , a Teca Electromyograph and stimulator (model B2) were used. These units were replaced with DISA electromyographs (models $14 \mathrm{~A} 30$ and model $14 \mathrm{~A} 4$ ) with DISA stimulator compatible with the electromyograph (model 14E 11 and Model 14E 12). Muscles were examined for insertional activity, spontaneous activity in resting muscle and patterns of electrical activity in contracting muscle. The potentials were led off from the muscles with a concentric needle electrode. In the studies of nerve conduction velocity, the evoked potentials were picked up with surface electrodes. The stimulus was applied to the skin over the ulnar nerve at the wrist and either at the elbow or at points approximately 50 millimeters proximal and distal to the elbow. The rate of stimulation was one per second and the duration of the stimulus was 0.1 millisecond.

\section{Results (Table III)}

In the 35 cases the youngest patient was 21 and the oldest 78 years of age. The majority were in the middle age group. Four were under 35 and four were over 65 years of age. Thirty of the patients were men and five were women. Seven of the patients had cardiovascular surgery, fourteen had orthopaedic surgery, two had genito-urinary surgery, nine had abdominal surgery and two had plastic 


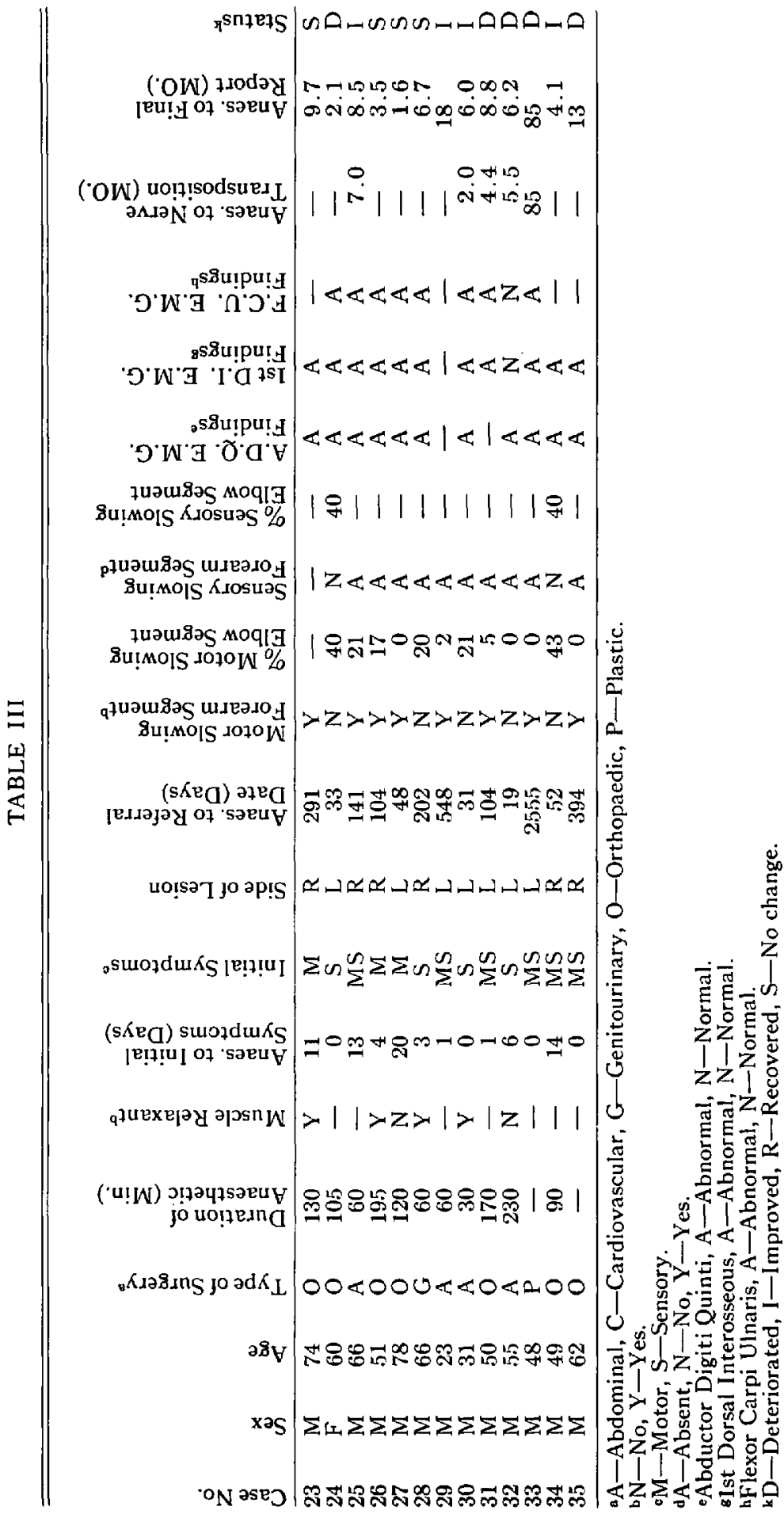


surgery. In one case the type of surgery was not reported. The type of anaesthetic used included thiopentone, methoxyflurane, halothane, fentanyl citrate-droperidol, nitrous oxide and tetracaine. Succinylcholine chloride was used as a neuromuscular blocking agent in 14 cases. The duration of anaesthesia varied from 30 minutes to 395 minutes.

It was difficult to establish accurately the exact time when the first sign of an ulnar nerve lesion appeared. Nine of the patients were aware of symptoms when they wakened from the anaesthetic and 13 patients reported symptoms during the first post-operative week. The times reported for the remaining 13 patients were estimated from notes on hospital records and from patients' reports. Some of the patients were not sure of the exact time because they were very ill during the postoperative period and were receiving intensive care. It appeared that early signs or symptoms of ulnar nerve pathology may have been missed by staff and patient when the patients were hurting in many places due to incisions and the necessary life-saving therapeutic procedures. Fifteen patients gave both motor and sensory symptoms in their initial complaint. Thirteen patients noted numbness and tingling before weakness. Five patients noticed weakness before any sensory symptoms. Two patients reported sensory symptoms but no weakness. In 20 cases the lesion was on the left, in $\mathbf{1 4}$ cases the lesion was on the right and in one case the lesions were bilateral.

There was a wide variation in the interval between the anaesthetic and the time of referral for electrodiagnostic examinations. The shortest period was nine days and the longest was seven years. Ten patients were referred during the first postoperative month. Five of these (cases 10, 15, 16, 20 and 32) plus case 31 were referred for repeat examination during the first post-operative year. Thirteen patients were referred by surgeons, two by internists, ten by neurologists and ten by physiatrists.

There were clinical conditions which might have made the ulnar nerve more vulnerable in 10 cases. In cases 10,23 and 35, there was a history of mild diabetes; in cases 17 and 34 there was a history of alcoholism; in cases 5,8 and 24 there was a history of arthritis; in case 27 there was a history of hemiplegia and in case 12 there was a history of Crohn's disease. In these cases, the electrophysiological findings supported a diagnosis of neuropathy due to compression rather than a diagnosis of peripheral neuropathy of an axonal or demyelinating type.

In 27 cases, reports were available which described the patient's condition after a period of three months or more from the time of surgery. Two patients had recovered, eight had improved, nine had not changed and eight had deteriorated. In cases 20 and 24 , symptoms increased during the first two months. Operation for transposition of the ulnar nerve was carried out in 12 cases.

Electromyography and nerve conduction velocity studies showed abnormalities which gave support to a diagnosis of a lesion in the ulnar nerve in the 35 cases. In 23 cases the electrophysiological findings helped to localize the site of the lesion as being at the level of the elbow. In the six cases which were referred for repeat examinations the findings supported improvement of the lesion in two cases and deterioration in four cases.

There was no obvious relationship between the severity and duration of the 
symptoms and the age, sex, surgical operation, type and duration of anaesthetic, onset of symptoms or predisposing causes.

\section{Discussion}

In 1966, Marinacci ${ }^{31}$ published a report on the electromyogram in the evaluation of nerve injuries occurring in hospitalized patients. He pointed out the importance of making an electromyographic referral as soon as the patient complains of any sensory or motor deficit with follow-up studies after a period of three weeks from time of appearance of symptoms or time of operation. In cases of injury of the ulnar nerve at time of operation, active denervation potentials should not appear until approximately three weeks after the event, and should be confined to the neuromuscular pathway of the ulnar nerve. If active denervation potentials occur at an earlier date the factor responsible for sensory disturbance or muscle weakness was pre-existing and not the result of injury at the time of operation. Electromyography is also useful for following the progression of the lesion.

Nerve conduction studies are helpful in localizing the site of a lesion and in estimating the degree of severity. Simpson ${ }^{32}$ was the first to report that there was local slowing in conduction velocity of motor fibres in a chronic traumatic lesion at the elbow. Gilliatt and Thomas ${ }^{33}$ reported that in nine cases of clinically established lesions of the ulnar nerve at the elbow, no sensory potential could be recorded at the wrist or proximal to the elbow. Kaeser, ${ }^{34}$ using surface recording electrodes, found that when there was a lesion of the nerve at the elbow the sensory potential at the wrist was either absent or too small to measure. $\mathrm{He}$ was able to localize 25 of 29 lesions at the elbow by stimulating the nerve proximal and distal to the elbow and demonstrating slowed motor conduction in the affected segment. Payan ${ }^{12}$ was only able to localize 13 of 50 lesions by clinical examination, but localized 48 of 50 lesions by using needle electrodes and recording motor and sensory conduction time, the latency to the flexor carpi ulnaris with stimulation proximal to the elbow, and sensory potential changes. Decrease of motor and sensory velocity in the segment crossing the elbow is not considered to have localizing value unless it is disproportionately lower than in the forearm. It must be remembered that electrophysiological studies are an extension of the physical examination.

The principal factor causing the majority of peripheral nerve injuries in anaesthetized patients is ischaemia which results from stretching or compression of the nerve. The ischaemia is of intraneural rather than extraneural origin (Britt and Gordon $\left.^{8}\right)$. The experimental work of Denny-Brown and Brenner ${ }^{21}$ and DennyBrown and Doherty ${ }^{22}$ demonstrated the mechanics and pathology of paralysis of nerve induced by direct pressure and by tourniquet and the effects of transient stretching of peripheral nerve. They pointed out that with compression of short segments of peripheral nerve, there is a great variation in the rate and extent of impairment of conduction due to the degree of ischaemia. This variability is related to the gradients of pressure in the tissues where anatomical structures provide compartments of differing rigidity and also to the length of the nerve over which the pressure is applied. The duration of the pressure required to cause 
paralysis appears to be highly variable. They graded the effects of pressure on conduction as of four degrees: nil; paralysis with rapid complete recovery on release of pressure; paralysis with delayed recovery without degeneration; and complete anatomical lesion with degenerative phenomena. They drew special attention to the third degree which represents a lesion lasting from $1^{-}$to 19 days, possibly longer, without signs of loss of excitability below the lesion, with preservation of gross sensation and retention of normal appearance of motor end plates and muscle fibres. Their grade 3 is similar to Seddon's ${ }^{23}$ neuropraxia where there is no evidence of axonal degeneration, but where slight myelin degeneration at the site of the trauma may be present.

The signs and symptoms of pathology in the ulnar nerve are not difficult to detect but localizing the site of the lesion, estimating the grade of severity and establishing the time of onset and the factors involved in the aetiology may present problems.

Certain anatomical features of the ulnar nerve contribute to its vulnerability and to the difficulty in localizing the site of the lesion. The intraneural arrangement of the nerve trunk at the site of compression affects its susceptibility to injury. Sunderland $^{24}$ reports that the vulnerability of a nerve is enhanced when it is composed of one major funiculus, a variable number of fine satellite fibres and a relatively small amount of epineural tissue. This is the topography of the ulnar nerve at the elbow. Because it is one of the long nerves of the body there is a greater possibility for injury (Nicholson and Eversole ${ }^{6}$ ).

At the level of the elbow, the ulnar nerve is in a superficial and vulnerable position. It passes from the surface of the triceps muscle to reach a position behind the medial epicondyle and medial to the ulnar collateral ligament and the olecranon process. The course of the nerve changes from superficial to submuscular when it dips through the restricted opening between the ulnar and humeral heads of the flexor carpi ulnaris. The roof of the opening is formed by an aponeurotic arch stretching between the medial epicondyle and the olecranon where the two heads of the flexor carpi ulnaris are attached. The floor is formed by the medial ligaments of the elbow joint (Feindel and Stratford ${ }^{25}$ ). Osborne ${ }^{26}$ described the band of fibrous tissue at the base of the aponeurosis and pointed out that the band is slack in full extension but when the elbow is flexing from $180^{\circ}$ it starts to tighten at $135^{\circ}$ and at $90^{\circ}$ is quite taut. In the flexed position, the capacity of the tunnel formed by the band and the joint is reduced. Ordinarily the ulnar nerve is capable of tolerating sufficient stretch to compensate for motion at the elbow (Conway ${ }^{27}$ ). Any process or anomaly which alters the normal anatomical relation of the ulnar nerve at the elbow or any intrinsic damage which impairs its elasticity may increase its vulnerability and may cause progression of a lesion after removal of compression (Estridge and Smith ${ }^{18}$ ). Osborne ${ }^{26}$ was of the opinion that in some individuals simple flexion of the elbow causes tingling in the little and ring fingers, and temporary neuritis after operations may be due to sleeping with the elbow flexed.

One anomaly which has been reported by a number of authors is exaggerated mobility of the nerve at the level of the elbow. The incidence has varied in different series. Childress ${ }^{16}$ found either complete or incomplete dislocation of the ulnar nerve in 16.2 per cent of 2,000 cases, and Ashenhurst ${ }^{28}$ found abnormalities 
in 22 per cent of 300 patients who were examined. The opinion of Britt and Gor$\mathrm{don}^{8}$ was that in over 20 per cent of cases the ulnar nerve pursues a more medial course than that described in standard texts, passing behind the backward projecting tip of the epicondyle rather than in the more protected groove. They illustrate how the nerve in these cases may be injured if the arms are held in a flexed position during surgery. Payan ${ }^{12}$ found 20 per cent of 48 patients had ulnar nerves which dislocated at the elbow. He considered that this made the nerves more vulnerable but that dislocation per se was not the cause of the lesions.

Denny-Brown and Brenner ${ }^{21}$ found that failure of nerve conduction due to compression was selective in that conduction of motor impulses failed before transmission of sensation. Woltman, ${ }^{11}$ in reporting on immediate injury of the ulnar nerve in cases of fractures, stated that generally motion and sensation are affected, but if either is spared that this is usually sensation. Brooks ${ }^{2 \theta}$ stated that if the compression is mild, the motor fibres are affected and there will be complete sparing of sensibility. In our cases, only five patients reported weakness as the initial symptom. It has been our impression that some patients do not complain of weakness until they notice difficulty in using their hand when they return to their usual activities.

Woltman $^{11}$ reported that ulnar palsy, incurred on the operating room table, occurs five times as often among men as among women and that left and right nerves are involved equally. In 33 reported cases, where patients were identified by sex, there were 29 males and 4 females. In our cases, the ratio was 6 males to one female. In compression injuries of the ulnar nerve at the level of the elbow not all nerve fibres are affected to the same degree and the lesions are, in general, incomplete. In all of our cases there was some degree of residual function.

In lesions at the elbow, the flexor carpi ulnaris muscle and the flexor digitorum profundus muscle may be spared. Vanderpool ${ }^{30}$ noted that the nerve bundles to the forearm muscles lie deeply in the nerve and theoretically therefore are least affected by compression on the superficial aspects of the nerve. Feindel and Stratford ${ }^{25}$ thought that the flexor digitorum profundus muscles may sometimes be spared in the lesion at the elbow because of an overlap in the innervation from the median nerve. The first dorsal interosseous muscle may be more involved than the hypothenar muscles (Osborne, ${ }^{26}$ Payan ${ }^{12}$ ). In 19 of our cases, where there was slowing in the motor conduction velocity in the segment of the ulnar nerve crossing the elbow, the flexor carpi ulnaris was spared in five cases. In two of our cases denervation potentials were observed in the first dorsal interosseous muscle but not in the abductor digiti quinti or flexor carpi ulnaris.

The number of referrals to our laboratory does not give an accurate indication of the frequency of compression neuropathy in the ulnar nerve following an anaesthetic, but shows that these cases continue to occur. These lesions are obviously not frequent, but any disability which appears to be iatrogenic in origin must continue to be examined carefully. Our follow-up studies, although inadequate, show that in some cases the lesions may be progressive and lead to a functional disability as well as the annoying distress of sensory deficits. It is our opinion that it is important to record in detail the patient's symptoms and the physical findings, when the patient makes the first complaint, and to try to establish whether or not 
the onset of the lesion was before, during or after the anaesthetic. Signs of preoperative injury or mild peripheral neuropathy may easily be missed in the preoperative examination when attention has been focused on the patient's surgical problems and life sustaining systems.

In terms of the patient's discomfort and the physician's discomfiture, it is not important whether the compression injury was sustained on the operating room table, on the stretcher, or on the bed in the recovery room. Britt and Gordon ${ }^{8}$ stated that compression may be caused by the sharp edge of the table if the elbow is allowed to sag just slightly over its side. They also pointed out that when a patient's arm was folded across the abdomen or chest, the stretching of the nerve by acute flexion of the elbow and the pressure exerted by the weight of the arm may be sufficient to produce ischaemia.

Routine procedures which are directed towards preventing the injury are obviously the best approach to the problem. One simple pre-operative precaution would be to place a foam rubber or plastic pad with adhesive backing over the medial aspect of the elbow. Other measures such as the use of wider tables and stretchers, examinations of restricting bandages, tapes and arm boards when it is necessary to re-position the arm and careful attention to the positioning of the arms when patient is being transferred from bed, table or stretchers should be part of the routine care. If a patient complains of symptoms which are diagnosed as a compression or stretching injury of an ulnar nerve he should be encouraged to avoid direct pressure over the nerve and positions of the arm which increase the symptoms. At the time of discharge from hospital the family physician should receive a report of the findings and symptoms. Patients should be examined at regular intervals to assess progress and to determine whether or not operation to transplant the ulnar nerve is advisable.

\section{SUMMARY}

Information regarding 35 patients who developed signs and symptoms of lesions in the ulnar nerve during the post-anaesthetic period, has been reported. The pertinent anatomical and physiological factors in the aetiology of compression neuropathy of the ulnar nerve have been summarized. The use of electromyography and nerve conduction studies has been discussed in relation to localizing the site, following the progression, estimating the severity of a lesion and helping to differentiate between a recent or a pre-operative lesion.

Lesions of the ulnar nerve continue to occur in patients who receive an anaesthetic. In our cases the severity of the lesions was not related to age, sex, type of operation or anaesthetic or the duration of the anaesthetic. Compression neuropathies of the ulnar nerve occurred more commonly in males than females. They may lead to a prolonged disability. Preventive measures and the importance of adequate follow-up have been discussed briefly.

\section{RÉSUMÉ}

C'est depuis 1901 que l'on rapporte dans les annales médicales des cas de névrite cubitale de compression survenant en cours d'anesthésie. 
Cette étude porte sur 35 cas qui nous furent dirigés pour électro-diagnostic entre 1965 et 1974.

Après avoir résumé les éléments anatomiques et physiologiques impliqués dans l'étiologie de cette affection, l'article présente les données électro-diagnostiques.

Dans cette série, la gravité des lésions n'était ni en fonction de l'âge, ni du sexe des malades, non plus que du type de chirurgie ou de la durée de l'anesthésie.

L'incidence cependant était plus élevée chez les hommes.

Cette affection peut conduire à une incapacité prolongée. Les auteurs recommandent, comme mesure de prévention: l'utilisation de coussins protecteurs au niveau des coudes et l'emploi de tables d'opération et de civières plus larges. Il faut porter une attention particulière à la position des bras, aux pansements, fixations, etc.

Les malades porteurs de cette névrite, méritent d'être examinés à intervalle régulier en vue d'évaluer la récupération et orienter le traitement.

\section{REFERENCES}

1. Budinger, K. Arch. Klin. Chirc, 47: 121 (1894).

2. Garruques, H.J. Anaesthesia-paralysis. Am. J. M. Sc. 133: 81 (1897).

3. Wood, D.A. Injuries to nerves during anesthesia. Calif. \& Western Md. 53: 267 (1940).

4. Clausen, E.G. Postoperative ("anaesthetic") paralysis of brachial plexus. Surgery 12: 933 (1942).

5. Slocum, H.C., O'Neal, K.C., \& AlLen, C.R. Neurovascular complications from malposition on the operating table. Surg. Gynec. \& Obst: 86: 720 (1948).

6. Nicholson, M.J. \& Eversole, U.H. Nerve injuries to anesthesia and operation. Anesth. \& Analg. 36: 19 ( 1957).

7. LinColN, J.R. \& SAwyer, H.P. Complications related to body positions during surgical procedures. Anesthesiology 22: 800 (1961).

8. Brirt, B.A. \& Gondon, R.A. Peripheral nerve injuries associated with anaesthesia. Can. Anaesth. Soc. J. 11: 514 (1964).

9. JoNEs, H.D. Ulnar nerve damage following general anaesthetic. Anaesthesia 22 , No. 3 : 471 (1967).

10. Wylde, W.D. \& Churchild-Davidson, H.C. Neurological and ophthalmic complications of anaesthesia. In: A Practice of Anaesthesia, 3rd ed. Chicago, Year Book Medical Publishers, p. 1262 (1972).

11. Woltman, H.W. Neuritis and other diseases or injuries of peripheral nerves. In: Tice's Practice of Medicine. Hagerstown, Md., W.F. Prior Co., Inc., Vol. 9, pp. 365-365A (1952).

12. Payan, J. Electrophysiological localization of ulnar nerve lesions. J. Neurol. Neurosurg. Psychiat. 32: 208 (1969).

13. De LEON. Paralysie du nerf cubital et contracture consecutive main en pince. Nouvelle Iconographie de la Salpetriere 14: 409 (1901).

14. GurdjIAN, E.S. Traumatic ulnar neuritis due to strapping of the elbow and the forearm to the operating table. J.A.M.A. 96: 944 (1931).

15. DhUNER, K.G. Nerve injuries following operations: a survey of cases occurring during a six-year period. Anesthesiology $11: 289$ ( 1950$)$.

16. Childress, H.M. Recurrent ulnar-nerve dislocation at the elbow. J. of Bone and Joint Surgery 38-A: 978 (1956).

17. Mumenthaler, M. Die ulnarisparesen. Stuttgart: George Thieme Verlag. p. 406 (1961).

18. Estridge, M.N. \& Sмrth, R.A. Compression neuropathy of the ulnar nerve. California Medicine 97: 71 ( 1962).

19. Copr, E.P. Compression neuropathy of the ulnar nerve at the elbow. Ann. Phys. Med. 8: $30(1965)$.

20. ENGKvIST, O. Postoperative ulnarispareser. Läkartidningen 69: 3425 (1972).

21. Denny-Brown, D \& Brenner, C. Paralysis of nerve induced by direct pressure and by tourniquet. Arch. of Neurol. and Psych. 51 : 1 (1944).

22. Denny-Bhown, D. \& Doherty, M.M. Effects of transient stretching of peripheral nerve. Arch. Neuro. Psychiat. 54: 116 (1945). 
23. SEddon, H.J. Three types of nerve injury. Brain 66: 238 (1943).

24. Sundenland, S. The applied anatomy of nerve trunks in relation to nerve injury. Internal features. In: Nerves and Nerve Injuries, Edinburgh and London, E. \& S. Livingston Ltd., Chap. 14, p. 199 (1968).

25. Feindel, W. \& Stratford, J. The role of the cubital tunnel in tardy ulnar palsy, Canad. J. Surg, 1: 287 (1958).

26. Osbonne, G.C. The surgical treatment of tardy ulnar neuritis. J. of Bone \& Joint Surgery 39-B: 782 (1957).

27. Conway, F.M. Traumatic ulnar neuritis. Ann. Surg. 97: 425 (1933).

28. Ashenhurst, E.M. Anatomical factors in the etiology of ulnar neuropathy. C.M.A.J. 87: 159 (1962).

29. Brooks, D.M. Nerve compression syndromes. J. of Bone \& Joint Surgery 45-B: 445 ( 1963 ).

30. Vandenpool, D.W. Peripheral compression lesions of the ulnar nerve. J. of Bone \& Joint Surgery 50-B: 792 (1968).

31. MarunacCI, A.A. The electromyogram in the evaluation of nerve inuries in hospitalized patients. Electromyography 6: 235 (1966).

32. Simpson, J.A. Electrical signs in the diagnosis of carpal tunnel and related syndromes. J. of Neurol. Neurosurg. \& Psychiat. 19: 275 (1956).

33. Gilliatt, R.W. \& Thomas, P.K. Changes in nerve conduction with ulnar lesions at the elbow. J. of Neurol. Neurosurg. \& Psychiat. 23: 312 (1960).

34. KaEser, H.E. Erregungsleitungsstörungen Bei Ulnarisparesen. Dtsch. Z. Nervenheilk. 185: 231 (1963). 